\title{
PROSPECTS FOR USE OF TECHNICAL CYBERNETICS IN ANIMAL HUSBANDRY
}

\author{
Oksana Mamai ${ }^{1}$, Sergey Mashkov ${ }^{1}$, Velta Parsova ${ }^{2}$ \\ ${ }^{1}$ Samara State Agricultural Academy, Russia; \\ ${ }^{2}$ Latvia University of Life Sciences and Technologies, Latvia \\ mamai_ov@ssaa.ru,mash_ser@mail.ru,velta@parsova.lv
}

\begin{abstract}
Digitization of technological processes in the past few decades is one of the actively developing areas of scientific thought. This is due to improvement of the computer technology, software and is determined by the need to optimize technological processes in various sectors of economy in general, and in animal husbandry in particular. Scientific basis and methodology for creation and operation of automated process control systems (ACS TP) is developed by technical cybernetics. Within this scientific discipline, there is its own arsenal of methodological and technical tools, the basic basis of which is the use of strictly formalized models for describing objects and their management objectives. Within these models, the locations for fixing technological information, its volumes, processing algorithms, forms of storage and types of practical use are clearly defined. The operation of any technological equipment must be supported by its internal control system at an optimal level. In this case, the design of the control system itself does not matter. The only important thing is that it is an inseparable attribute for any production process and technical device that has a non-zero set of operating states. This class of objects includes almost all agricultural machinery, mechanized processes and technologies. In conducting this study, such methods as monographic, analytical, abstract-logical, economic-statistical, scientific deduction and induction, comparison, quantitative and qualitative analysis, mathematical modeling, and others were used. As a result of the study, from the standpoint of technical cybernetics, the prospects for its use in animal husbandry to solve many management tasks, including solving problems of managing a dairy farm, and improving the efficiency of basic technological operations, were studied.
\end{abstract}

Keywords: cybernetics, animal husbandry, productivity, efficiency, control.

\section{Introduction}

The new century has set new problems for humanity, in particular: how to feed the growing population of the planet, how to meet the demand for high-quality food products, how to increase labour productivity in organizations of the agrarian sector of the economy. New automation technologies and information technologies can help in their solution.

Dairy cattle breeding is the most difficult and labor-intensive industry of animal husbandry. From these positions, the use of technical cybernetics for solving problems of managing a dairy farm and increasing the efficiency of performing basic technological operations is of scientific and practical interest.

Industrial milk production technology is a production process for processing feed into animal products (milk and meat) in large mechanized farms and complexes [1]. From a cybernetic point of view, a dairy herd is a dynamic self-replicating object, which, under the conditions of the limiting environmental factors, converts one type of nutrients into another. A herd of one unit is one animal. In technical systems, environmental factors are sought to be minimized, whereas in biotechnical systems, environmental performance is maintained at a comfortable level, at which animal life functions best. The above can be presented in the form of a cybernetic "black box" model (Fig. 1)

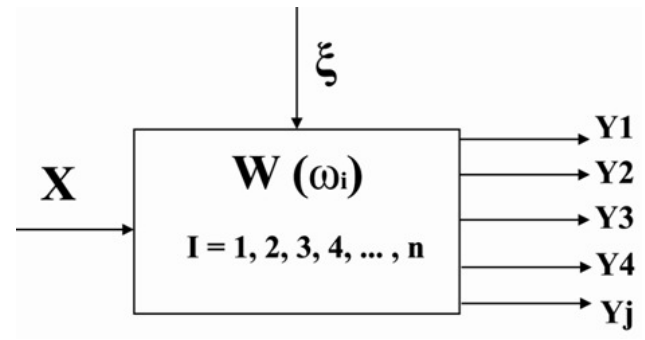

Fig. 1. Cybernetic model of cow: $X$ - vector of input nutrients; $\xi$ - vector of animal environmental factors; $Y_{1}$ - milk; $Y_{2}-$ meat; $Y_{3}$ - organic fertilizers; $Y_{4}$ - litter; $Y_{j}-$ other output indicators (heat, unwanted gases, methane, carbon dioxide, etc.), odors, etc.; $\mathrm{W}$ - transfer function of the animal

(mathematical model of the animal)

In the general case, the output indicators of cow productivity are described by function (1): 


$$
\mathrm{Y}_{\mathrm{j}}=\mathrm{f}(\mathrm{X}, \xi, \omega), \mathrm{j}=1,2,3,4, \ldots, \mathrm{m}
$$

where $Y_{j}-$ scalar values of output indicators of productivity;

$\mathrm{X}, \xi, \omega-$ vectors characterizing the parameters of input nutrients, environmental conditions and internal (breeding) properties of the animal.

The level of modern achievements does not yet allow explicitly describing for each animal its exact functional dependencies of the output indicators of productivity on the conditions of housing and feeding. Therefore, in the actual process of livestock production, it is necessary to use simplified approximation models based on observations of input and output effects. The methodology for obtaining them is currently well developed in the rapidly developing scientific field "applied statistics". The accuracy of the description of production processes by their approximative models depends largely on the volume and completeness of the experimental data.

The global goal of productivity management is to continuously increase [2]. To solve this problem without knowing the functional dependencies of animal productivity on changes in the conditions of their housing and feeding is almost impossible. Due to this circumstance, an appropriate system for collecting the necessary technological information must operate on any managed production farm. The principles of organizing such a system and the range of tools used in it range from manual methods of fixing technological information to using fully automated information and measurement devices [3]. The current state of development of electronics and computing equipment is such that there are all the prerequisites for mass introduction of automated technological information collection systems at dairy farms [4-6]. Thus, based on the results of the study, the authors proposed to use technical cybernetics for effective management of dairy farms. It allows differentially to take into account the influence of each factor on the final results of the facility's work, and also provides a quantitative assessment of the performance of specific performers.

\section{Materials and methods}

The research materials were scientific works of domestic and foreign scientists in the field of technical cybernetics, applied statistics, automation technologies and informatization, etc. In conducting this study, such methods as monographic, analytical, abstract-logical, economic-statistical, scientific deduction and induction, comparison, quantitative and qualitative analysis, mathematical modeling, and others were used.

\section{Results and discussion}

There are two known methods for solving the global problem of increasing the productivity of animals: breeding and economic [7].

The selection method involves the improvement of the internal properties of the object $(\omega=$ var), that is, breeding of new breeds of cattle. For this method, the factors $X, \xi$ are considered to be predetermined and meet the requirements of $X, \xi=$ const. Theoretically, this method has unlimited possibilities.

The economic method has a clear limit, which is determined by the individual potential breeding abilities of the animal $(\omega=$ const), which can only be realized by regulating the factors $X, \xi=$ var.

Thus, the task of managing a dairy farm is to bring its work to the optimum level of productivity $\left(\mathrm{Y}_{\mathrm{opt}}\right)$ and maintain it in this state for a long time (Fig. 2).

For all the obviousness and simplicity of the formulation of the formulated problem, its solution turns out to be an extremely difficult problem, since there are no clear criteria that unequivocally indicate the degree of remoteness of the actual production facility from its limit state. The generally accepted criteria of the economic efficiency, built on the comparison of the results of the economic activity of the object with the cost of their implementation, are of little use here. Thus, the profit indicator, which is the difference between the revenue of the sold products and the cost of their production $\left(\mathrm{P}=\mathrm{S}_{1}-\mathrm{Z}\right)$, is not based on any reasonable limits. Here, the higher the profit, the more efficient the production.

It is unreasonable to lay such an indefinite criterion of the state of production in formalized optimal control algorithms. Here we need fundamentally new ways of determining the effective state 
of a dairy farm and adequate evaluation criteria adequate to them. This condition is most fully satisfied by the criteria of the maximum normalized method of comparative analysis.

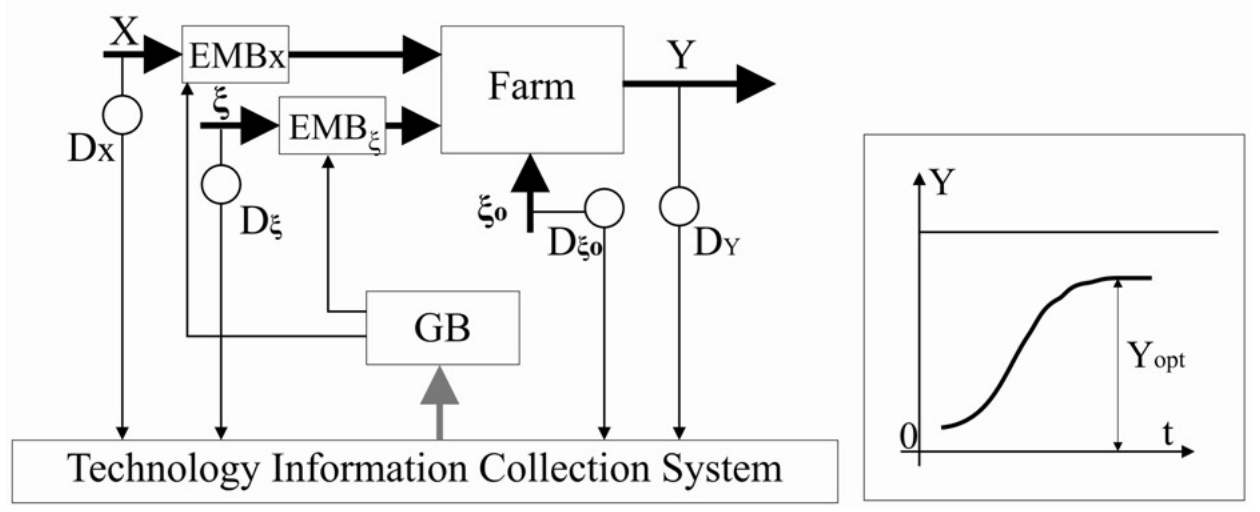

Fig. 2. Generalized block diagram of dairy farm management system: GB - governing body; EMB - executive management bodies; D - primary devices for obtaining and recording technological information (sensors); $\xi_{0}, \xi$ - regulated and unregulated environmental factors of the animal

The idea of this method is that as a basic reference level corresponding to the maximum possible productivity of the herd takes the performance of an abstract object endowed with ideal properties [8]. Such an object works in real conditions, produces meat and dairy products of the highest quality without material costs and with strict implementation of all the rules of the technological process. Taking the performance of such an object as a basic basis (100\%), it is possible to evaluate the efficiency of a real object by the degree of its performance indicator approaching the accepted limit value. Due to the limitations imposed by the action of objective material laws, real objects can only approach this state.

The costs of implementation of the technological process of production of livestock products, as well as the proceeds from its sale are estimated, as a rule, in monetary units. This circumstance determined the methodology and the general structure of the system of extremely normalized criteria (2):

$$
\Psi=\left(\mathrm{S}_{1}-\mathrm{Z}\right) \div \mathrm{S}_{0}^{-1}
$$

where $\Psi$ - limit normalized criterion;

$\mathrm{S}_{1}, \mathrm{~S}_{\mathrm{o}}$ - cash value of the output products derived from real and ideal objects;

$\mathrm{Z}$ - real costs of implementation of the technological process of livestock production (cost of production).

The ratio $\alpha=\mathrm{S}_{1} \cdot \mathrm{S}_{\mathrm{o}}^{-1}$ is the coefficient of utilization of economic productivity. In this expression the unknown quantity is $S_{0}$. However, it is easy to determine from the same data that were used to calculate $S_{1}$. If we take into account the breeding properties of livestock, then $S_{o}$ means the herd productivity, in which there are no diseases and deaths, the intensity of the appearance of lactation periods is optimal (all animals go into a state of pregnancy when inseminated into the second hunt), the milk yield is equal to the average values for the breed, and all products are sold on the market in the highest quality category. Any deviations from these requirements lead to losses, the value of which is determined by the experimental data.

The general tendency to improve any technological process, including the process of producing meat and dairy products, is to reduce the costs of its production and sale, improve the quality of output products and reduce losses, that is, $\mathrm{Z} \rightarrow \mathrm{Z}_{\min }, \mathrm{S}_{1} \rightarrow \mathrm{S}_{\mathrm{o}}$.

When $Z_{\min }=0$, the criterion $\Psi$ of a real object in the limit tends to unity, which in this method is taken as a constant base of comparison. A value of $0<\Psi<1$ indicates a positive profitability of the process, a value of $\Psi<1-$ negative. The boundary of the transition corresponds to the equality $\Psi=0$.

The actual value of the criterion $\Psi$ does not depend on the number of the herd, fluctuations in the purchase prices and zonal conditions for animals. It is fully determined only by the degree of deviation of the actual technological process from the ideal, the implementation of which is provided for in the same production conditions. 
From the point of view of the tasks of planning and managing the technological process, the equality $\mathrm{R}+\alpha=1$ is important, where $\mathrm{R}$ - reserve for increasing the economic productivity of the dairy herd.

The reserve is the difference between the actual results of the farm and the "ceiling" of its extreme technological capabilities. Science is constantly striving to raise the absolute "ceiling" of animal breeding as high as possible. However, the breeding and subsequent distribution of a new breed of livestock takes many years and therefore dairy farms have been working for a long time in a constant "ceiling" of productivity. This situation entails a number of consequences.

1. A real increase in farm productivity can only be achieved through realization of the existing reserves. Moreover, due to the action of objective laws, it is not possible to realize the entire reserve, but only some part of it. The state of the technological process, in which the maximum possible part of the total reserve is realized, is called the optimal. The scientific methods of bringing the controlled object into the optimal zone are developed by the theory of optimal systems. However, the choice and justification of the optimality criterion is beyond the scope of this science.

2. The presence of marginal productivity (ceiling) casts doubt on the validity of applying the widely used method of planning and stimulating effective work of an agricultural enterprise from the level achieved. For farms that have reached optimal levels of productivity such planning is completely devoid of any meaning.

In the framework of the proposed method, the indicator characterizing the general reserve of productivity has the property of additivity, that is, $R=\sum r_{i}$, where $r_{i}$ is a private (differentiated) reserve from not using the possibilities of the i-th factor. In general, there are many such factors, but the largest share falls on five:

- calving intensity;

- animal diseases;

- case (disposal of animals);

- livestock maintenance (feeding, care, habitat comfort);

- grade of products.

Full use of the livestock potential is achieved only in terms of its comfortable maintenance (care, rational and balanced nutrition, proper microclimate in the room, etc.). Therefore, the factor of keeping animals is itself integrated and, if necessary, it can be dissected into its component parts.

The criterion $\Psi$ is related to the return on the investment indicator $\beta=S_{1} \cdot Z^{-1}$ and the coefficient of utilization of economic productivity $\alpha=\mathrm{S}_{1} \cdot \mathrm{S}_{\mathrm{o}}^{-1}$ (3):

$$
\Psi=\alpha \cdot\left(1-\beta^{-1}\right)=(1-\mathrm{R}) \cdot\left(1-\beta^{-1}\right) .
$$

From the analysis of the above formulas it can be seen that the linear operations of addition, subtraction, and multiplication are used at all stages of the transformation $\mathrm{R} \rightarrow \alpha \rightarrow \Psi$. Therefore, the additive property of the criterion $\mathrm{R}$ is successively transmitted to $\alpha$ and further to $\Psi$ (4):

$$
\alpha=\sum \alpha_{\mathrm{i}}, \Psi=\sum \Psi_{\mathrm{i}} .
$$

This property is useful from the point of view of analysis and management decision-making, since it allows differentially to take into account the influence of each factor on the final results of the object's work. As a rule, specific performers are clearly visible behind each factor. Therefore, the criteria under consideration can be used to quantify the effectiveness of their work.

\section{Conclusions}

1. Digitization of technological processes in the past few decades is one of the actively developing areas of scientific thought. Scientific basis and methodology for creation and operation of automated process control systems is developed by technical cybernetics.

2. As a result of the study, from the standpoint of technical cybernetics, the prospects for its use in animal husbandry to solve many management tasks, including solving problems of managing a dairy farm, and improving the efficiency of basic technological operations, were studied. 
3. The use of technical cybernetics for effective management of dairy farms allows to differentially take into account the influence of each factor on the final results of the facility, and also provides a quantitative assessment of the performance of specific contractors through effective collection of technological information.

4. Use of technical cybernetics allows to calculate the most effective options for managing dairy farms.

\section{References}

[1] Ковалев Ю.Н. Технология и механизация животноводства (Technology and mechanization of livestock). Moscow, 2000. 242 p. (In Russian).

[2] Nipers A., Pilvere I., Valdovska A., Proskina L. Assessment of key aspects of technologies and cow farming for milk production in Latvia. Proceedings of 15 th International Scientific Conference "Engineering for Rural Development", May 25-27, 2016, Jelgava, Latvia, pp. $175-181$.

[3] Антамошин А.Н., Близнова О.В., Бобов А.В. Интеллектуальные системы управления организационно-техническими системами (Intellectual control systems of organizational and technical systems). Moscow, 2016. 160 p. (In Russian).

[4] Плахин Е.С., Золотарева Е.Л. Инновационное развитие, как детерминанта повышения эффективности функционирования сельского хозяйства (Innovative development as a determinant of improving the efficiency of agriculture). Bulletin of the Kursk State Agricultural Academy, vol. 4, 2013, pp. 33-35. (In Russian).

[5] Рунов Б.А. Применение робототехнических средств в АПК (The use of robotic tools in agriculture). Bulletin of the All-Russian Research Institute of Livestock Mechanization, vol. 2 (18), 2015, pp. 41-43. (In Russian).

[6] Nemeiksis A., Osadcuks V. Robot movement planning and control intelligent system in unknown environment. Proceedings of 17th International Scientific Conference "Engineering for Rural Development”, May 23-25, 2018, Jelgava, Latvia, pp. 948-957.

[7] Войнова Н.Ф. Современное состояние теории, средств и методов автоматизации технологических процессов сельскохозяйственного производства (The current state of the theory, means and methods of automation of technological processes of agricultural production). Bulletin of the All-Russian Research Institute of Electrification of Agriculture, vol. 2 (15), 2014, pp. 64-67. (In Russian).

[8] Харазов В.Г. Интегрированные системы управления технологическими процессами (Integrated process control systems). Vologda, 2013. 550 p. (In Russian). 